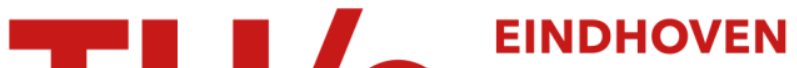

\section{Temperature-dependent built-in potential in organic semiconductor devices}

\section{Citation for published version (APA):}

Kemerink, M., Kramer, J. M., Gommans, H. H. P., \& Janssen, R. A. J. (2006). Temperature-dependent built-in potential in organic semiconductor devices. Applied Physics Letters, 88(19), 192108-1/3. [192108]. https://doi.org/10.1063/1.2205007

DOI:

10.1063/1.2205007

Document status and date:

Published: 01/01/2006

\section{Document Version:}

Publisher's PDF, also known as Version of Record (includes final page, issue and volume numbers)

\section{Please check the document version of this publication:}

- A submitted manuscript is the version of the article upon submission and before peer-review. There can be important differences between the submitted version and the official published version of record. People interested in the research are advised to contact the author for the final version of the publication, or visit the $\mathrm{DOI}$ to the publisher's website.

- The final author version and the galley proof are versions of the publication after peer review.

- The final published version features the final layout of the paper including the volume, issue and page numbers.

Link to publication

\section{General rights}

Copyright and moral rights for the publications made accessible in the public portal are retained by the authors and/or other copyright owners and it is a condition of accessing publications that users recognise and abide by the legal requirements associated with these rights.

- Users may download and print one copy of any publication from the public portal for the purpose of private study or research.

- You may not further distribute the material or use it for any profit-making activity or commercial gain

- You may freely distribute the URL identifying the publication in the public portal.

If the publication is distributed under the terms of Article $25 \mathrm{fa}$ of the Dutch Copyright Act, indicated by the "Taverne" license above, please follow below link for the End User Agreement:

www.tue.nl/taverne

Take down policy

If you believe that this document breaches copyright please contact us at:

openaccess@tue.nl

providing details and we will investigate your claim. 


\title{
Temperature-dependent built-in potential in organic semiconductor devices
}

\author{
M. Kemerink, ${ }^{\text {a) }}$ J. M. Kramer, H. H. P. Gommans, and R. A. J. Janssen \\ Department of Applied Physics, Eindhoven University of Technology, P.O. Box 513, 5600 MB Eindhoven, \\ The Netherlands
}

(Received 23 August 2005; accepted 21 April 2006; published online 12 May 2006)

\begin{abstract}
The temperature dependence of the built-in voltage of organic semiconductor devices is studied. The results are interpreted using a simple analytical model for the band bending at the electrodes. It is based on the notion that, even at zero current, diffusion may cause a significant charge density in the entire device, and hence a temperature dependent band bending. Both magnitude and temperature dependence of the built-in potential of various devices are consistently described by the model, as the effects of a thin LiF layer between cathode and active layer. (C) 2006 American Institute of Physics. [DOI: 10.1063/1.2205007]
\end{abstract}

Optimal performance of bipolar devices such as lightemitting diodes (LEDs) and photovoltaic (PV) cells generally requires the presence of Ohmic electron and hole contacts. ${ }^{1}$ Since an Ohmic electron contact is usually nonOhmic for holes, and vice versa, different contacts for electrons and holes are used in most optimized devices. This results in asymmetric current-voltage $(I-V)$ characteristics. In the field of organic electronics this asymmetry is commonly described in terms of a built-in voltage $V_{\mathrm{bi}}{ }^{2}$ In Fig. 1(a) a typical band diagram is shown, defining this quantity. In principle, the work functions $\chi_{i}$ of the metallic contacts and the relative positions of the highest occupied molecular orbital (HOMO) and lowest unoccupied molecular orbital (LUMO) levels of the organic material(s) in the actual device, i.e., $\varphi_{1}$ and $\varphi_{2}$, can be determined by (inverse) photoemission spectroscopy. ${ }^{3,4}$ In the interpretation of the $I-V$ characteristics of such devices, the onset voltage $V_{0}$ of strong carrier injection is normally taken as indicative of the socalled flatband condition sketched in Fig. 1(a). Alternatively, the open circuit potential $V_{\text {oc }}$, defined as the potential at which the device current under illumination equals zero, is used. In the band diagram of Fig. 1(a) one has indeed $V_{\mathrm{bi}}$ $=V_{0}=V_{\mathrm{oc}}$. Experimentally, $V_{0}$ and $V_{\mathrm{oc}}$ usually differ significantly from $\chi_{1}-\chi_{2}$ (and $E_{g}-\varphi_{1}-\varphi_{2}$ ).

Since the work of Simmons ${ }^{5}$ it is known that significant band bending may occur in the vicinity of metal contacts, which leads to a reduction $\Delta V_{0}$ of the voltage at which flatband is reached in the bulk of the device, see Figs. 1(b) and 1(c). When the energy difference between band and Fermi level is only a few times $k_{B} T$ or less, as is the case near an Ohmic contact, the band bending may be $0.2 \mathrm{eV}$ or more. Recently, Mihailetchi et al. used this model to describe the nonlinear dependence of $V_{\text {oc }}$ of organic solar cells on the cathode work function. ${ }^{6}$ Unfortunately, the expressions for the potential distribution $V(x)$ that follow from this and other, fully electrostatic models that are based on the concept of Fermi level alignment require numerical evaluation.,6

In this work, we show that $V(x)$ can be analytically calculated from the drift-diffusion and Poisson equations by realizing that the equilibrium space charge in the lowconductivity material is determined by a balance of drift and

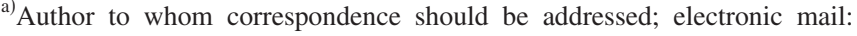
m.kemerink@tue.nl diffusion currents. We use our model to interpret experiments on the temperature dependence of $V_{0}$ in organic LEDs and PV cells.

Although the drift-diffusion equations have no general analytic solution, one can obtain one for zero net injection into a semi-infinite slab of semiconducting matter. Starting from the drift-diffusion equation for a single charge carrier,

$$
j=e \mu n E+e D \frac{d n}{d x}=0,
$$

with $j$ and $n$ are the current and carrier densities, $\mu$ and $D$ are the mobility and diffusion constant, that are related via the Einstein relation $D=\mu k T / e$, and the Poisson equation,

$$
\frac{d^{2} V}{d x^{2}}=-\frac{d E}{d x}=\frac{e n}{\varepsilon_{0} \varepsilon_{r}},
$$

with $\varepsilon_{0} \varepsilon_{r}$ the dielectric constant of the material, we arrive at the following nonlinear differential equation:

$$
E \frac{d E}{d x}+\frac{k T}{e} \frac{d^{2} E}{d x^{2}}=0
$$

which can be solved to yield

$$
E=\frac{2 k T}{e} \frac{1}{x+x_{0}} \text { and } V=-\frac{2 k T}{e}\left(\ln \frac{x+x_{0}}{x_{0}}\right) .
$$

The free parameter $x_{0}$ can be used to match the carrier density at the contact according to

$$
n(x=0)=\frac{2 k T \varepsilon_{0} \varepsilon_{r}}{e^{2}} \frac{1}{x_{0}^{2}}=\min \left[n_{0} \exp \left(-\frac{\varphi}{k T}\right), n_{0}\right],
$$

with $\varphi$ the barrier for charge injection and $n_{0}$ the density of states in the insulator. Note that the solution (4) is independent of the carrier mobility. In Fig. $2 V(x)$ and $n(x)$ are plotted versus depth for different temperatures. The reduction in band bending with decreasing $T$ directly reflects the decrease in diffusion constant, leading to a lower carrier density in the layer, and, via the Poisson equation, to a reduced curvature of $V(x)$, and hence to an increased $V_{0}$, see Fig. 1(c).

It is easy to verify that Eqs. (4) and (5) exactly reproduce the outcome of the model in Ref. 5 for a semi-infinite system.

The question remains how the band bending is to be determined in an actual device since $V(x)$ is experimentally 

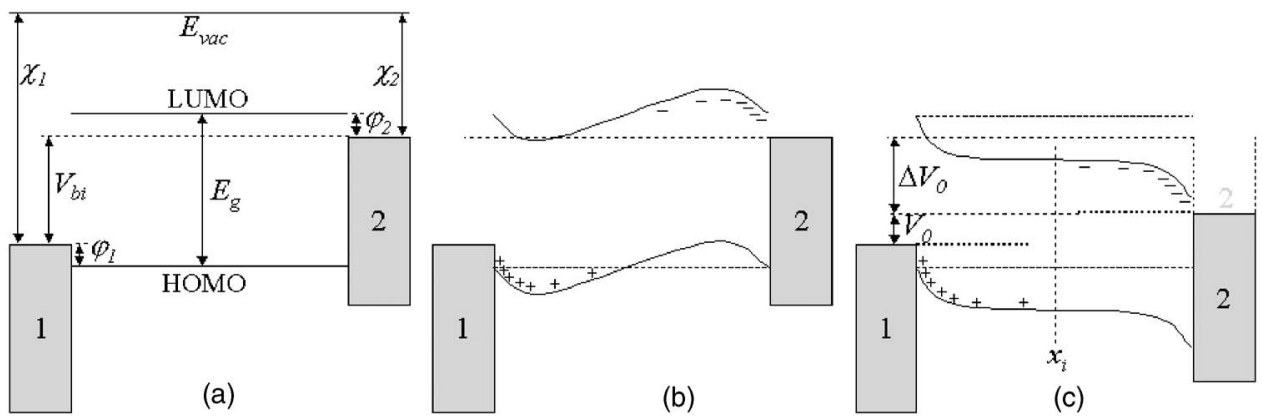

(c)

FIG. 1. (a) Schematic band diagram at $V=V_{\mathrm{bi}}$ of a typical bipolar device, ignoring band bending. Gray areas indicate metallic contacts; in the used devices 1 is PEDOT:PSS and 2 is either Al or LiF/Al. (b) At the same bias as under (a), band bending due to carrier diffusion from the contacts results in a nonzero field in the bulk. In order to achieve flatband in the bulk again, the bias must be reduced from $V_{\text {bi }}$ to $V_{0}$ (c). The thick dashed lines indicate the electron and hole quasi-Fermi levels, see text.

virtually inaccessible. ${ }^{4,8,9}$ For a device that is connected to external terminals, the condition $J=0$ by definition applies at zero bias. However, since the charge density in the vicinity of the contact is much higher than the densities associated with space-charge limited conduction (SCLC), it is reasonable to take the onset of SCLC, which occurs when flatband is reached in the bulk of the device, as a first-order approximation for the flatband condition [Fig. 1(c)]. This onset corresponds to $V_{0}$ as defined above, and is commonly referred to as the built-in voltage., ${ }^{2,10,11}$

Comparison of Eq. (4) to experimental values of $V_{0}$ is not straightforward since Eq. (4) is derived for $J=0$ in a single-carrier, semi-infinite system. However, in Fig. 2 it can be seen that the majority of the diffusion-induced band bending occurs in the direct vicinity of the contact. A lowest order extension of the model to an actual bipolar device at $V=V_{0}$ is therefore to split the device into independently treated electron- and hole-dominated areas, where the crossover occurs at depth $x_{i}\left(x_{i} \in[0, d]\right.$ with $d$ the active layer thickness) where $n\left(x_{i}\right)=p\left(x_{i}\right)$, which simultaneously yields continuity of $E$. Given the strong depth dependence of the density (Fig. 2), it is justifiable that the 'local minority' carrier and recombination are ignored. ${ }^{12}$ In this approximation, the Fermi levels in the electron and hole dominated regions should be regarded as (electron and hole) quasi-Fermi levels, which is consistent with the notion that at the onset at SCLC a small nonequilibrium diffusion current flows in the device.

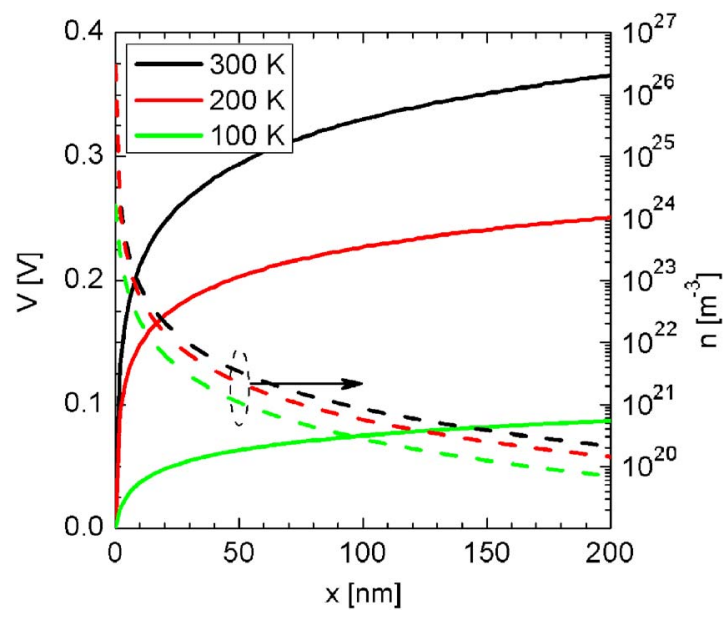

FIG. 2. (Color online) Calculated potential $V$ (left axis) and density $n$ (right axis) vs $x$ for different temperatures. The metallic contact is located at

$x<0$. Used parameters: $\varphi_{1}=0.1 \mathrm{eV}, n_{0}=3 \times 10^{26} \mathrm{~m}^{-3}$, and $\varepsilon_{r}=3$. T $\quad T 00 \mathrm{~K}$ (top) to $80 \mathrm{~K}$ (bottom). Arrows indicate the position of $V_{0}$.
Downloaded 05 Feb 2007 to 131.155 .151 .20 . Redistribution subject to AIP license or copyright, see http://apl.aip.org/apl/copyright.
Devices were made by spin coating poly(2-methoxy-5$\left(3^{\prime}, 7^{\prime}\right.$, -dimethyloctyloxy)-1,4-phenylene vinylene) (MDMO-PPV) (140 nm), 1-(3-methoxycarbonyl)propyl-1phenyl-[6,6]-fullerene (PCBM) $(56$ and $20 \mathrm{~nm})$, or a $1: 4$ mass ratio MDMO-PPV:PCBM blend $(100 \mathrm{~nm})$ from chlorobenzene on poly(3,4-ethylenedioxythiophene):poly(4styrenesulfonate) (PEDOT:PSS) $(80 \mathrm{~nm})$ covered indium tin oxide (ITO) glass substrates. The top electrode was formed by evaporation of $1 \mathrm{~nm} \mathrm{LiF}$ (optional) and $100 \mathrm{~nm} \mathrm{Al}$. Subsequently, the samples were mounted on the cold finger of an evacuated flow cryostat without making contact with air.

$V_{0}$ has been determined by subtraction of the low-field "leakage current" from the forward diode characteristics and subsequent extrapolation of the "real" device current to zero, as indicated in the inset of Fig. 3. The results from repeated measurements on multiple samples of each type are collected in Fig. 3. For some samples, the temperature range over which reliable data could be obtained is limited by the relatively large contribution of the leakage current to the total current at lower temperatures. For all samples, the typical spread in the obtained values of $V_{0}$ at any temperature is about $0.1 \mathrm{eV}$.

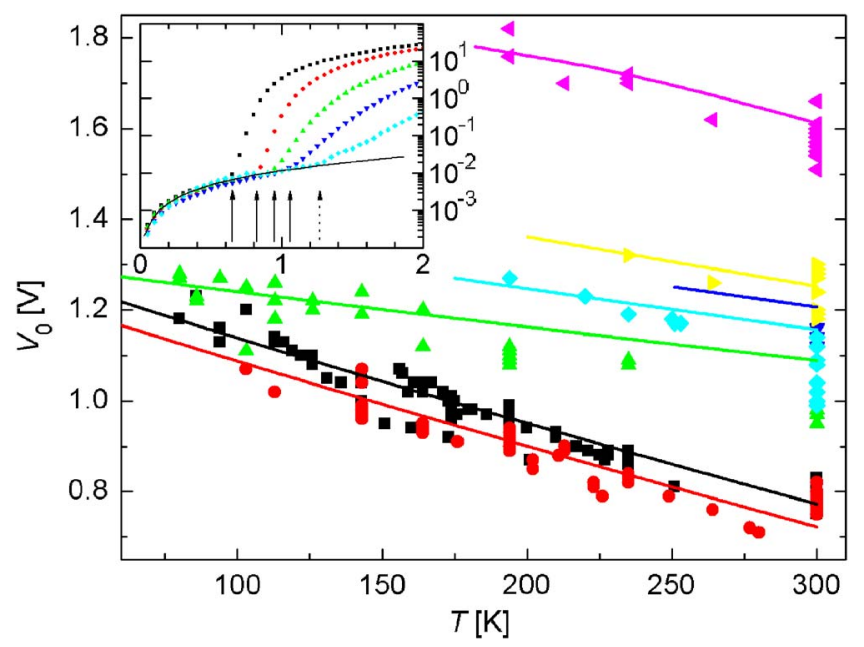

FIG. 3. (Color online) $V_{0}$ vs $T$ for all studied devices. Symbols indicate experimental data, lines are model calculations, using the parameters given in Table I, and $n_{0}=3 \times 10^{26} \mathrm{~m}^{-3}$ (Ref. 6). $\mathbf{\square}$ : blend+LiF; : blend, no LiF; $\boldsymbol{\Delta}: \mathrm{PCBM}+\mathrm{LiF}(20 \mathrm{~nm}) ; \boldsymbol{\nabla}: \mathrm{PCBM}+\mathrm{LiF}(56 \mathrm{~nm}) ;$ $(56 \mathrm{~nm}) ;$ ४: MDMO-PPV+LiF; : MDMO-PPV, no LiF. The inset shows typical $J$ (in $\mathrm{mA} / \mathrm{cm}^{-2}$ ) vs $V$ (in volts) curves of a blend sample for

$T=300 \mathrm{~K}$ (top) to $80 \mathrm{~K}$ (bottom). Arrows indicate the position of $V_{0}$.
to AIP license or copyright, see http://apl.aip.org/apl/copyright.jsp 
TABLE I. Parameters used in the model calculations. $V_{0}$ is calculated as $V_{0}=E_{g}-\varphi_{h}-\varphi_{e}-V\left(x_{i}, x_{0}^{h}\right)-V\left(L-x_{i}, x_{0}^{e}\right)$ with $V$ given by Eq. (4), $x_{i}$ the crossover depth (see text), and $x_{0}^{e / h}$ the boundary condition for the electron/hole contact from Eq. (5). The uncertainty in all energies is around $0.1 \mathrm{eV}$. In the calculations, the values of $E_{g}$ are reduced by $5 / 9 \sigma^{2} / k_{B} T$ with $\sigma$ the broadening of the density of states (DOS) to account for the fact that the transport level in a Gaussian DOS lays below its center (Ref. 6). For the same reason, the obtained values for $\varphi$ have to be regarded as lower limits. For MDMOPPV $\sigma=0.11 \mathrm{eV}$ and for PCBM $\sigma=0.072 \mathrm{eV}$ (Ref. 6).

\begin{tabular}{lccc}
\hline \hline & & & $\begin{array}{c}\text { MDMO-PPV/PCBM } \\
\text { blend }\end{array}$ \\
\hline$\varphi_{\text {PEDOT }}(\mathrm{eV})$ & 0 & PCBM & 0 \\
$\varphi_{\mathrm{Al}}(\mathrm{eV})$ & 0.65 & 0.05 & 0.05 \\
$\varphi_{\mathrm{LiF} / \mathrm{Al}}(\mathrm{eV})$ & 0.25 & -0.05 & 0 \\
$E_{g}(\mathrm{eV})$ & $2.5^{\mathrm{a}}$ & $2.4^{\mathrm{a}, \mathrm{b}}$ & $1.65^{\mathrm{b}}$ \\
$\varepsilon_{r}$ & 3 & $3.9^{\mathrm{b}}$ & 3.72 \\
\hline \hline
\end{tabular}

${ }^{\mathrm{a} \text { Reference } 13 \text {. }}$

${ }^{\mathrm{b}}$ Reference 6.

Clearly, in all studied devices $V_{0}$ shows a similar increase with decreasing temperature, which evidently cannot be explained by a band diagram as sketched in Fig. 1(a). By contrast, the model outlined above gives an adequate description of all experimental data, using a limited number of free parameters. Only the injection barrier heights of pure MDMO-PPV and PCBM are adjusted to fit the data, the barrier heights for the blend are taken as the lowest value of the two pure materials. All other parameters are taken from literature. The used parameters are given in Table I and the caption of Fig. 3. The validity of our approach is further corroborated by the injection barrier values found in this procedure. The obtained hole injection barriers $\left(\varphi_{\text {PEDOT }}\right)$ agree well with literature values in the range of $0-0.1 \mathrm{eV}$ for the PEDOT:PSS/MDMO-PPV interface, ${ }^{6,13}$ and $0.8-1 \mathrm{eV}$ for the PEDOT:PSS/PCBM interface. ${ }^{6,13,14}$ The low electron injection barriers $\left(\varphi_{\mathrm{Al}}\right.$ and $\left.\varphi_{\mathrm{LiF} / \mathrm{Al}}\right)$ found for the interfaces with PCBM also agree well with earlier measurements. 6,13 For the MDMO-PPV/Al and MDMO-PPV/LiF/Al interfaces we are not aware of any explicit measurement of the electron injection barriers. However, the change of $0.4 \mathrm{eV}$ in $V_{0}$ due to the insertion of the $\mathrm{LiF}$ layer, as calculated from our model for $T=77 \mathrm{~K}$, corresponds well to the value of $0.5 \mathrm{eV}$ reported in Ref. 15. Note that at room temperature the LiFinduced change is only $0.3 \mathrm{eV}$.

Finally, it is worthwhile to point out that our results offer a simple explanation for the common observation that $V_{0}$ of optimized devices is typically several hundredths of $\mathrm{eV}$ below what is expected on basis of the work function difference of the electrodes, i.e., $V_{0}<\chi_{1}-\chi_{2}$.

In conclusion, we have successfully explained the magnitude and temperature dependence of the built-in voltage of organic semiconductor devices in terms of temperature dependent charge diffusion from the metallic contacts into the organic layer. The diffused charge causes a band bending which leads to the observed behavior of the built-in voltage. We derived an analytical model that is able to quantitatively describe the experimental observations. Given the rather general considerations that underlie the model, we expect that it is applicable to any contact between a metallic material, i.e., a material having a high free carrier density, and a material with a low free carrier density, i.e., a $n_{\text {free }} \ll n(x$ $=0$ ) as defined by boundary condition Eq. (5).

${ }^{1}$ M. Pope and C. E. Swenberg, Electronic Processes in Organic Crystals and Polymers, 2nd ed. (Oxford University Press, Oxford, 1999).

${ }^{2}$ G. G. Malliaras, J. R. Salem, P. J. Brock, and J. C. Scott, Phys. Rev. B 58, R13411 (1998).

${ }^{3}$ See, e.g., A. Kahn, N. Koch, and W. Gao, J. Polym. Sci., Part B: Polym. Phys. 41, 2529 (2003).

${ }^{4}$ I. H. Cambell, T. W. Hagler, D. L. Smith, and J. P. Ferraris, Phys. Rev. Lett. 76, 1900 (1996).

${ }^{5}$ J. G. Simmons, J. Phys. Chem. Solids 32, 1987 (1971).

${ }^{6}$ V. D. Mihailetchi, P. W. M. Blom, J. C. Hummelen, and M. T. Rispens, J. Appl. Phys. 94, 6849 (2003).

${ }^{7}$ C. M. Ramsdale, J. A. Barker, A. C. Arias, J. D. MacKenzie, R. H. Friend, and N. C. Greenham, J. Appl. Phys. 92, 4266 (2002).

${ }^{8}$ T. M. Brown, R. H. Friend, I. S. Mikllard, D. J. Lacey, J. H. Burroughes, and F. Cacialli, Appl. Phys. Lett. 77, 3096 (2000).

${ }^{9}$ M. Kemerink, P. Offermans, P. M. Koenraad, J. K. J. van Duren, R. A. J. Janssen, H. W. M. Salemink, and J. H. Wolter, Phys. Rev. Lett. 88, 096803 (2002).

${ }^{10}$ Any systematic errors made by taking $V_{0}$ as indicative of $V_{\mathrm{bi}}$ will most likely not influence the extracted $T$ dependence. In PV devices, also $V_{\text {oc }}$ can be taken, which, however, has the disadvantage that significant photogenerated space charges may be present in the device, see, e.g., L. J. A. Koster, E. C. P. Smits, V. D. Mihailetchi, and P. W. M. Blom, Phys. Rev. B 72, 085205 (2005); H. H. P. Gommans, M. Kemerink, J. M. A. Kramer, and R. A. J. Janssen, Appl. Phys. Lett. 87, 122104 (2005).

${ }^{11}$ G. G. Malliaras, J. R. Salem, P. J. Brock, and J. C. Scott, J. Appl. Phys. 84, 1583 (1998).

${ }^{12}$ Note that this method calculates the band bending inside the device, i.e., $\Delta V_{0}$ in Fig. 1(c). When $T \rightarrow 0, \Delta V_{0} \rightarrow 0$, and $V_{0} \rightarrow E_{g}-\varphi_{1}-\varphi_{2}$.

${ }^{13}$ C. Melzer, E. J. Koop, V. D. Mihailetchi, and P. W. M. Blom, Adv. Funct. Mater. 14, 865 (2004).

${ }^{14}$ J. K. J. van Duren, V. D. Mihailetchi, P. W. M. Blom, T. von Woudenbergh, J. C. Hummelen, M. T. Rispens, R. A. J. Janssen, and M. M. Wienk, J. Appl. Phys. 94, 4477 (2003).

${ }^{15}$ J. Reynaert, Y. D. Jin, T. Aernouts, W. Geens, G. Borghs, R. Mertens, and P. Heremans, Mater. Res. Soc. Symp. Proc. 771, L10.29.1 (2003). 